\title{
Toll-like receptor expression and function in human dendritic cell subsets: implications for dendritic cell-based anti-cancer immunotherapy
}

\author{
Gerty Schreibelt • Jurjen Tel · Kwinten H. E. W. J. Sliepen • \\ Daniel Benitez-Ribas · Carl G. Figdor · Gosse J. Adema • \\ I. Jolanda M. de Vries
}

Received: 8 January 2010 / Accepted: 8 February 2010 / Published online: 5 March 2010

(C) Springer-Verlag 2010

\begin{abstract}
Dendritic cells (DCs) are central players of the immune response. To date, DC-based immunotherapy is explored worldwide in clinical vaccination trials with cancer patients, predominantly with ex vivo-cultured monocyte-derived DCs (moDCs). However, the extensive culture period and compounds required to differentiate them into DCs may negatively affect their immunological potential. Therefore, it is attractive to consider alternative DC sources, such as blood DCs. Two major types of naturally occurring DCs circulate in peripheral blood, myeloid DCs (mDCs) and plasmacytoid (pDCs). These DC subsets express different surface molecules and are suggested to have distinct functions. Besides scavenging pathogens and
\end{abstract}

This paper is a Focussed Research Review based on a presentation given at the Ninth International Conference on Progress in Vaccination against Cancer (PIVAC 9), held in Sofia, Bulgaria, 8-10 October 2009.

G. Schreibelt · J. Tel · K. H. E. W. J. Sliepen · C. G. Figdor ·

G. J. Adema · I. J. M. de Vries ( $\square)$

Department of Tumor Immunology,

Nijmegen Centre for Molecular Life Sciences, Radboud University Nijmegen Medical Centre PO Box 9101, 6500 HB Nijmegen, The Netherlands

e-mail: j.devries@ncmls.ru.nl

D. Benitez-Ribas

Department of Gastroenterology,

CIBERehd, Hospital Clinic, Barcelona, Spain

\section{J. M. de Vries}

Department of Medical Oncology,

Radboud University Nijmegen Medical Centre,

Nijmegen, The Netherlands

\section{J. M. de Vries}

Department of Paedriatric Hemato-Oncology,

Radboud University Nijmegen Medical Centre,

Nijmegen, The Netherlands presenting antigens, DCs secrete cytokines, all of which is vital for both the acquired and the innate immune system. These immunological functions relate to Toll-like receptors (TLRs) expressed by DCs. TLRs recognize pathogenderived products and subsequently provoke DC maturation, antigen presentation and cytokine secretion. However, not every TLR is expressed on each DC subset nor causes the same effects when activated. Considering the large amount of clinical trials using DC-based immunotherapy for cancer patients and the decisive role of TLRs in DC maturation, this review summarizes TLR expression in different DC subsets in relation to their function. Emphasis will be given to the therapeutic potential of TLR-matured DC subsets for DC-based immunotherapy.

Keywords Dendritic cell vaccination - Myeloid dendritic cells · Plasmacytoid dendritic cells · Toll-like receptors

\section{Introduction}

To date, dendritic cell (DC)-based immunotherapy is explored worldwide in clinical vaccination trials, predominantly in cancer patients (reviewed in [1]). The therapy consists of autologous ex vivo-cultured, antigen-loaded monocyte-derived DCs (moDCs) or $\mathrm{CD}_{4} 4^{+}$progenitorderived DCs that are administered to patients with the intention of inducing antigen-specific $\mathrm{T}$ and $\mathrm{B}$ cell responses. The generation of anti-tumor immune responses involves the induction of Th1-type $\mathrm{CD} 4^{+} \mathrm{T}$ cells and $\mathrm{CD} 8^{+}$cytotoxic $\mathrm{T}$ lymphocytes. Although DC-based immunotherapy potently induces immunological responses, thus far only a limited number of clinical responses have been observed [2]. It is unclear whether DCs differentiated ex vivo from precursor cells are the most optimal source of DCs for the induction of 
potent immune responses. The extensive culture period (89 days) and compounds required to differentiate them into DCs may negatively affect DC function, especially migration $[3,4]$. Therefore, it is attractive to consider alternative DC sources, such as blood DCs. Two major types of DCs circulate in the blood, which can be distinguished by the presence of different surface markers: myeloid dendritic cells (mDCs) and plasmacytoid dendritic cells (pDCs).

In melanoma patients, we demonstrated that moDC maturation is a prerequisite for the generation of tumor-specific $\mathrm{T}$ cell responses [5]. While blood DCs may not require extensive culture, for these cells activation is essential prior to reinfusion, as immature DCs may cause tolerance rather than immunity. To date, most clinical studies use TNF $\alpha$, IL- $1 \beta$, IL-6 and prostaglandin $\mathrm{E}_{2}$ for moDCs maturation. However, it has been suggested that the current protocols used to generate mature moDCs may not result in optimal Th1 responses. Murine studies have shown that activation of DCs by solely pro-inflammatory cytokines yields DCs that support $\mathrm{CD} 4^{+} \mathrm{T}$ cell clonal expansion, but fail to efficiently direct helper $\mathrm{T}$ cell differentiation. In contrast, exposure of DCs to pathogen associated molecular patterns (PAMPs) induces DCs that produce high levels of the Th1 skewing cytokine IL-12p70 and promote efficient $\mathrm{T}$ cell help. PAMPs are recognized by pattern recognition receptors (PRRs). MoDCs, mDCs and pDCs express different repertoires of PRRs and respond dissimilarly to extracellular stimuli, suggesting that the DC subsets have specialized and complementary functions [6]. In this review we summarize the expression of the most wellknown PRRs, Toll-like receptors (TLRs), on different DC subtypes in relation to their function.

\section{Dendritic cell subsets}

Dendritic cells are the most potent professional antigenpresenting cells (APC) of the immune system. Upon infection or inflammation, immature DCs are activated and differentiate into mature DCs that instruct and activate B and $\mathrm{T}$ lymphocytes, the mediators of adaptive immunity [7]. DCs take up and process pathogens and present pathogen-derived peptides to $\mathrm{T}$ cells via major histocompatibility complex (MHC) molecules. The recognition of the peptide-MHC complex (signal 1) and stimulation via costimulatory molecules (signal 2) and cytokines (signal 3) lead to the activation of $\mathrm{T}$ cells. The immunological outcome strongly depends on the activation state of DCs. Resting DCs or DCs receiving inhibitory signals, such as IL-10 or corticosteroids, induce immune tolerance via $\mathrm{T}$ cell deletion or induction of regulatory $\mathrm{T}$ cells, whereas mature DCs induce immunity.

The classical view of DCs is that of immature DCs, waiting for pathogens to be recognized, residing mainly in parts of the body that are in close contact with the outside world, such as skin and mucosal tissue. These immature DCs are able to quickly sense and take up pathogens that could harm the host. After recognition of a pathogen, the DCs mature and migrate to lymphoid tissues to present the pathogenic peptides to $\mathrm{T}$ cells [7]. DC maturation comprises a tightly controlled series of events, including downmodulation of endocytic and phagocytic receptors, upregulation of costimulatory molecules, such as CD40, CD58, CD80 and CD86, changes in morphology and reorganization of the DC lysosomal and MHC class II compartment. DC maturation is highly complex and should be regarded as a flexible process, the outcome of which depends on the type of signals a DC receives in the periphery.

The DC population is a heterogeneous population. The DC subtypes differ in function, localization and phenotype. In human peripheral blood, two main populations of DCs can be distinguished: CD11c expressing myeloid DCs (mDCs) and CD11c negative plasmacytoid DCs (pDCs) [8]. These DCs express distinct PRRs and respond to different pathogenic stimuli, suggesting that each subset has a specialized function in directing immune responses. However, both $\mathrm{mDCs}$ and $\mathrm{pDCs}$ have the capacity to initiate suitable $\mathrm{T}$ cell responses, depending on the pathogens they encounter.

\section{Plasmacytoid dendritic cells}

Human pDCs are a rare subpopulation of cells; they constitute only $0.1 \%$ of all blood mononuclear cells. PDCs are devoid of lineage markers and myeloid antigens and do not express CD11c. PDCs express BDCA2 and BDCA4 [9]. In the steady state, they are round, non-dendritic and relatively long-lived cells. After receiving inflammatory stimuli, pDCs develop dendritic cell morphology and function. Most notably, pDCs produce large amounts of type I interferons in response to viruses and are therefore crucial to antiviral immunity [10].

Initially, pDCs were thought to be of lymphoid origin [11]. However, several human and mouse studies pointed out that the cytokine Flt3L is of importance for $\mathrm{pDC}$ development and that pDCs can develop out of myeloid precursors under the influence of Flt3L [10, 12, 13]. PDCs reside in blood as well as in several lymphoid organs, and some recent studies suggest functional differentiation between different tissue-residing pDCs [14]. Whether these are actual pDC subsets or whether environmental factors influence pDC function is not clear yet.

\section{Myeloid dendritic cells}

Myeloid DCs found in peripheral blood are defined by the expression of myeloid markers, such as CD13 and CD33. They lack lineage-specific markers (CD3, CD14, CD19 and 
CD56), but express MHC class II and CD11c. The mDC population can be further subdivided based on differential surface expression of CD1c (BDCA1), CD16 and BDCA3. In addition, another small subset of CD16-expressing DC, termed M-DC8 DCs or SlanDCs, has been described [15]. CD16-mDCs comprise the largest population of mDCs (65$75 \%$ of total mDC population), followed by CD1c-mDCs $(10-20 \%)$ and BDCA3-mDCs $(3-5 \%)$ [16, 17]. Although CD16-mDCs have the highest frequency in human peripheral blood, CD1c-mDCs have been studied most extensively. The mDC subsets differ in their expression of cell surface markers and potency to stimulate $\mathrm{T}$ cells [16-18]. For instance, the recently identified C-type lectin receptor CLEC9a is expressed only by BDCA3-mDCs [19]. According to MacDonald et al. [16] CD1c-mDCs are the most potent $\mathrm{T}$ cell stimulators of the three $\mathrm{mDC}$ subpopulations.

\section{Monocyte-derived dendritic cells}

Since the frequency of circulating mDCs in human blood is very low, many studies exploit in vitro-generated "monocytederived dendritic cells" (moDCs) [20]. Monocytes are preDCs that originate from myeloid progenitor cells. In vivo, monocytes are capable of transforming into DCs after sensing inflammatory signals and are important for the replenishment of dendritic cells in the host. In vitro, a cocktail of granulocyte/macrophage colony-stimulating factor (GM-CSF) and interleukin-4 (IL-4) differentiates monocytes into moDCs [20]. MoDCs are the major DC type used in clinical DC vaccination studies $[2,21]$. Whether these moDCs reflect immature "steady state" in vivo mDCs remains to be seen, as most of these moDCs show a dramatically higher expression of MHC molecules and costimulatory molecules compared to freshly isolated immature mDCs [22]. In addition, moDCs and $\mathrm{mDCs}$ respond differently to physiologic stimuli and differ in their ability to stimulate $\mathrm{T}$ cells $[23,24]$. Therefore, although in vitro-generated moDCs share many phenotypic and functional characteristics with circulating $\mathrm{mDCs}$, it is yet unclear to what extend they resemble blood DCs.

In addition to monocytes, $\mathrm{CD} 34^{+}$precursors in blood are also used to generate DCs for vaccination of cancer patients. They consist of two populations: one with Langerhans celllike properties and one called interstitial/dermal DCs with properties resembling moDCs. Immunological and clinical responses have been observed in cancer patients vaccinated with CD34+-derived DCs [25]. However, to date most clinical studies use monocytes to generate DCs.

\section{Pathogen recognition by Toll-like receptors}

In evolution, the immune system has acquired various receptor families that recognize several crucial molecular components of pathogens. This set of PAMPs recognized by the immune system is limited and constituted mostly of general molecular patterns that are absent on cells of the host and are essential for survival of the microbe. On DC membranes, two main PRR families are present: C-type lectins and Toll-like receptors (TLRs), of which the TLR family is best characterized and recognizes the most diverse group of PAMPs. Nowadays, 15 mammalian Toll-like receptors are found (TLR1-15), of which 10 are in humans $[26,27]$. The binding partners of the recently discovered TLR10, TLR12, TLR13 and TLR15 are unknown. TLR11 is only expressed in mice and recent studies suggest that TLR11 associates with molecules originating from uropathogenic bacteria and Toxoplasma Gondii [28, 29]. The better-described TLR1-9 can be divided into two main groups: extracellular TLRs that are found on the cell surface (TLR1, TLR2, TLR4, TLR5 and TLR6) and the intracellular TLRs that are located in the endosomal compartments (TLR3, TLR7, TLR8 and TLR9). In general, intracellular TLRs recognize nucleotide-containing structures, for example RNA molecules (TLR3, TLR7 and TLR8) and unmethylated CpG DNA (TLR9), originating from viruses and bacteria. Extracellular TLRs recognize exterior components of bacteria and fungi, e.g., cell wall components. Examples of ligands include lipopolysaccharide (LPS) for TLR4, flagellin for TLR5 and peptidoglycan for TLR2. TLR2 forms heterodimers with either TLR1 or TLR6. The TLR1/ 2 heterodimer recognizes bacterial triacyl lipopeptides and TLR2/6 recognizes bacterial diacyl lipopeptides. Besides PAMPs derived from pathogens, TLRs have been proposed to recognize endogenous ligands such as heat-shock proteins or necrotic cells [30, 31]. The signaling pathways associated with ligation of the different TLRs are not identical and therefore distinct biological responses are initiated. Ligand binding of TLRs recruits one or more adaptor molecules. The difference in signaling outcome (e.g., variation in cytokine production) can be explained in part by the use of different adaptor molecules by the Toll-like receptors. All TLRs, except TLR3, rely on MyD88 for signal transduction. TLR3 uses TRIF as adaptor molecule, whereas TLR4 is able to recruit both MyD88 and TRIF [32].

\section{TLR expression and functionality in DC subpopulations}

DCs show different expression levels of TLRs and respond dissimilarly to TLR ligands. The expression of TLRs varies with species, DC subtype and maturation stage. In this review, we focus on TLR expression and function in human DC subsets. We have divided the human DC population into three groups: in vitro-generated moDCs and circulating $\mathrm{mDCs}$ and pDCs. Expression of TLRs and the effects of TLR activation in the three DC subtypes are summarized in Table 1. 
Table 1 TLR expression and functionality on DC subtypes

\begin{tabular}{|c|c|c|c|c|}
\hline DC subtype & TLR & Expression & Effects of activation & References \\
\hline \multirow[t]{15}{*}{ moDC } & 1 & + & See TLR2 & {$[35,39-41,44,71]$} \\
\hline & 2 & ++ & Increased IL-6, IL-8, IL-10, IL-12, TNF $\alpha$ & {$[35,38-41,44,71]$} \\
\hline & & & Low IFN $\beta$ response and no IFN $\alpha$ response & \\
\hline & 3 & + & Specific IFN $\beta$ mRNA upregulation (not IFN $\alpha$ ) & {$[35,38-41,44,71]$} \\
\hline & 4 & ++ & Upregulation of CD80, CD86, CD83, CCR7 & {$[35,38-41,44,71]$} \\
\hline & & & Secretion of IFN $\beta$, IFN $\gamma$, IL- $1 \beta$, IL-12p70, IL-13, IP-10 & \\
\hline & & & Decreased endocytic capacity & \\
\hline & 5 & + & Upregulation of CD80, CD86, CD83, CCR7 & {$[35,39-41,44,71]$} \\
\hline & & & Secretion of IFN $\gamma$, IL- $1 \beta$, TNF, IL-8, IL-12p40 (not IL-12p70), IL-13 & \\
\hline & & & Decreased endocytic capacity & \\
\hline & 6 & \pm & See TLR2 & {$[35,38,39,41,71]$} \\
\hline & 7 & \pm & - & {$[35,39,41,71]$} \\
\hline & 8 & + & Increased TNF $\alpha$, IL-8, IL-12p40, MCP-1, CCL2, CCL3, CCL4, CCL5 & {$[35,39,41,71]$} \\
\hline & 9 & - & & {$[35,39,41,71]$} \\
\hline & 10 & - & & {$[39,41]$} \\
\hline \multirow[t]{17}{*}{$\mathrm{mDC}$} & 1 & + & See TLR2 & {$[35-37,39,51]$} \\
\hline & 2 & ++ & Upregulation of CCR7, IL-6, IL-10, IL-12p70,TNF $\alpha$, no INF $\alpha$ & {$[35-39,51]$} \\
\hline & 3 & ++ & IFN $\alpha$ (intermediate), IL-12p70 (high) & {$[35-39,51]$} \\
\hline & & & No TNF $\alpha$ or IL-6 & \\
\hline & 4 & + & Upregulation of CD80, CD86, CD83, CD40, CCR7 & {$[34-39,51]$} \\
\hline & & & Secretion or upregulation of CCR7, IL-6, IL-8, IL-10, IL-12p70 & \\
\hline & & & No IFN $\alpha$ response & \\
\hline & 5 & + & Upregulation of CD80, CD86, CD83, CCR7 & {$[35-37,39]$} \\
\hline & & & Secretion of TNF and IL-8 & \\
\hline & & & Upregulation of CCR7 & \\
\hline & 6 & + & See TLR2 & {$[35-37,39,51]$} \\
\hline & 7 & + & Upregulation of CD40, CD80 and CD86 & {$[34-37,39,51]$} \\
\hline & & & Secretion of IL-12p70 & \\
\hline & & & No IFN $\alpha$ response & \\
\hline & 8 & \pm & See TLR7 & {$[35-37,39,51]$} \\
\hline & 9 & - & & {$[34-37,39,51]$} \\
\hline & 10 & + & No ligand known & {$[36,39,51]$} \\
\hline \multirow[t]{14}{*}{$\mathrm{pDC}$} & 1 & \pm & & {$[35-37,50,51]$} \\
\hline & 2 & - & & {$[35-38,50,51]$} \\
\hline & 3 & - & & {$[35-38,50,51]$} \\
\hline & 4 & - & & {$[34-38,50,51]$} \\
\hline & 5 & - & & {$[35-37,50]$} \\
\hline & 6 & - & & {$[35-37,50,51]$} \\
\hline & 7 & ++ & Upregulation of CD40, CD80, CD86, CCR7 & {$[34-37,50,51]$} \\
\hline & & & Very high IFN $\alpha$ response & \\
\hline & & & No IL-12p70 response & \\
\hline & 8 & - & & {$[35-37,50,51]$} \\
\hline & 9 & +++ & Upregulation of CD40, CD80, CD86, CD83, HLA-DR, CCR7 & {$[34-37,50,51]$} \\
\hline & & & $\begin{array}{l}\text { Upregulation of IFN } \alpha \text { (very high), IFN } \beta \text { (lower), } \\
\text { IL- } 6, \text { TNF } \alpha \text { (low), IL- } 8, \text { IP-10 }\end{array}$ & \\
\hline & & & No IL-10 secretion & \\
\hline & 10 & + & No ligand known & {$[36,50-52]$} \\
\hline
\end{tabular}


TLR expression and activation: moDCs and mDCs compared

DCs derived in vitro from monocytes (moDCs) have provided immunologists important insights into the biology of DCs. Because of the large amounts of clinical trials using moDCs as an alternative for naturally occurring blood mDCs, we here compare the TLR expression profile in human moDCs and their blood-isolated mDC counterparts. Of the three blood mDC subpopulations, CD1c-mDCs have been studied most extensively. Only a study by Piccioli et al. compared the expression and function of TLRs in the three circulating mDC subtypes, CD16-mDCs, CD1cmDCs and BDCA3-mDCs. They detected the expression of TLR1-10 at the RNA level in all three mDC subsets, with the exception of TLR3, which was not expressed by CD16mDCs. In addition, both CD16-mDCs and CD1c-mDCs strongly responded to all TLR agonists, except the TLR9 agonist $\mathrm{CpG}$. Interestingly, CD16-mDCs were responsive to the TLR3 ligand poly(I:C), while TLR3-mRNA was not detected in these cells. The authors suggest that poly(I:C) may activate CD16-mDCs through TLR3-independent mechanisms [17], such as cytosolic RNA sensors like RIGlike helicases [33]. Another possibility may be that minor contaminations of, for instance, endotoxin in poly(I:C) have activated other TLRs. Due to the low frequency of BDCA3-mDC in peripheral blood, no functional studies were performed on this $\mathrm{mDC}$ subset.

Since other studies on TLR expression and function in $\mathrm{mDC}$ subtypes are lacking, we focused on CD1c-mDCs when comparing moDCs with blood mDCs. Human moDCs and CD1c-mDCs show very similar TLR expression profiles (Table 1). Both DC subsets express the extracellular TLRs (TLR1, TLR2, TLR4, TLR5 and TLR6) and the endosomal TLRs (TLR3 and TLR8) (Table 1). In addition, both moDCs and CD1c-mDCs respond to specific ligands of these TLRs, leading to a mature phenotype and production of proinflammatory cytokines [34-42]. However, some significant differences between moDCs and CD1c-mDCs in TLR expression and ligand reactivity were found.

Most notably, moDCs showed negligible TLR10 expression, whereas blood mDCs did express TLR10. An extensive qPCR expression profiling by Means et al. [39] revealed that $\mathrm{mDCs}$ have 20 -fold higher expression levels of TLR10 mRNA compared to moDCs. MRNA expression of TLR10 in mDCs was even comparable to that of TLR5. Unfortunately, the ligands and functionality of TLR10 are still unknown, so this difference between moDCs and mDCs could not be explained. However, since TLR10 is also expressed by regulatory T cells [43], TLR10 activation on DCs may induce tolerogenic DCs. The fact that moDCs have a more mature phenotype [22] may thus explain the absence of TLR10 in moDCs.
Iwasaki and Medzhitov [27] concluded that human mDCs totally lacked TLR4 expression. The authors mainly base their conclusion on a study performed by Visintin et al. [44]. However, their results were contradicted by Ito et al. [34] and Matsumoto et al. [38] in 2002 and 2003, respectively, who showed that freshly isolated human blood mDCs expressed TLR4. This was confirmed by experiments in the same study of Ito et al. [34] which showed that stimulation of mDCs with LPS induced the production of IL12. According to Means et al. [39] moDCs secrete type I IFNs on LPS administration, whereas this ligand did not provoke type I IFN secretion in mDCs. While this was confirmed by Matsumoto et al. [38], the function of type I IFN secretion after LPS challenge remains unclear, as type I IFNs have anti-viral rather than anti-bacterial properties. The disparity in IFN secretion may also be caused by the difference in maturation stage between moDCs and CD1cmDCs. Muzio et al. [40] showed that as differentiation of monocytes progresses toward moDCs, the expression of TLR 3, 4 and 5 increases. Eventually the expression of TLR4 in moDCs is higher than that in CD1c-mDCs. This higher number of TLR4 molecules per cell may explain the difference in type I IFN secretion between moDCs and CD1c-mDCs. A high number of TLR4 molecules might induce a broader immune response: a low number of TLR4 molecules is able to only activate the MyD88 pathway, resulting in an immune response without an IFN response, whereas a higher amount of TLR4 molecules might be able to activate both the MyD88 and TRIF pathway, leading to a broader immune response, including production of type IFNs [45]. This is in line with the finding that the TRIF adapter protein in non-plasmacytoid DCs is mainly responsible for the activation of transcription factors that induce type I interferons [45].

TLR1, 2 and 6 are expressed by both moDCs and mDCs (Table 1) [35-39, 41]. Through the formation of heterodimers with TLR1 or TLR6, TLR2 gains the capacity to bind a wide variety of bacterial and yeast-derived ligands. Consequently, this plays a central function in pathogen recognition by DCs. TLR1/2/6 activation leads to DC maturation and secretion of several cytokines important in immune system activation, especially IL-6, IL-8, IL-10, IL-12 and TNF- $\alpha$. Differences in expression between moDCs and mDCs in TLR1, TLR2 and TLR6 expression and reactivity are negligible.

TLR5 expression was evident in both moDCs and CD1c-mDCs as indicated in Table 1. Means et al. [39] especially investigated the role of TLR5 and its main ligand, bacterial flagellin, in moDCs and to a lesser extent in mDCs. They found increased surface expression of maturation markers for both, without the induction of a type I IFN response, which is expected considering the bacterial origin of flagellin. 
Studies on TLR7 expression on moDCs or mDCs show conflicting results. This inconsistency was also noted in the review by Iwasaki and Medzhitov [27]. It was especially fueled by the contradictory results of Jarossay et al. and Krug et al. [35]. Using three different primer sets for RTPCR on TLR7, Ito et al. [34] concluded that human mDCs do express TLR7. For TLR7 expression in moDCs, there is still disagreement between studies; however, the most recent findings suggest that moDCs indeed express TLR7 [39]. For moDCs, a thorough study of TLR7 mRNA/protein expression, as was performed for $\mathrm{mDCs}$ by Ito et al., is lacking. Confirmation of TLR7 protein expression is difficult due to low expression and a lack of good antibodies. Therefore, TLR7 expression in moDCs is still unclear, as indicated by the "+/-" in Table 1. TLR8, the "near cousin" of TLR7, was found to be consistently expressed in lower amounts in both moDCs and mDCs. As TLR7 and TLR8 share the same ligands, it was impossible to attribute TLR8 as the binding receptor responsible for the secretion of cytokines or DC maturation after, for example, R848 challenge [34].

Human moDCs and mDCs do not express TLR9 and do not respond to TLR9 ligands [34, 37]. TLR9 is only expressed by pDCs in the human setting and is responsible for a very high type I IFN response [46].

In summary, data suggest that both moDCs and mDCs express TLR1-8 and not TLR9, and only mDCs express TLR10. The mRNA expression of these receptors was confirmed by DC reactivity studies using TLR ligands, as summarized in Table 1.

\section{TLR expression by human pDCs}

Evidence suggests that pDCs are specialized in the recognition of viral antigens, as they largely lack expression of extracellular TLRs and only express TLRs that recognize and respond to viral antigens. PDCs abundantly express TLR7 and TLR9 in their endosomal compartments. In addition, triggering of TLR7 and TLR9 on pDCs leads to high type I IFN secretion and a typical mature DC phenotype, i.e., upregulation of expression of major histocompatibility molecules and the costimulatory molecules, CD80 and CD86.

Interestingly, it has been suggested that in human pDCs, TLR9 displays a unique feature that is not shared by the other described TLRs. Depending on the stimulus, activation of TLR9 on human pDCs can have a different outcome. The dual function of TLR9 is attributed to the distinct intracellular locations where TLR9 can be triggered. Upon encountering nucleic acids, TLR9 will traffic from the endoplasmatic reticulum through the Golgi to the early endosomes $[47,48]$. There, TLR9 triggering may induce the recruitment and phosphorylation of IRF7, which in turn induces IFN $\alpha$ secretion, thus activating an innate immune response. In contrast, in the late endosomes, TLR9 triggering preferentially activates NF- $\kappa \mathrm{B}$, which results in phenotypical maturation of DCs and secretion of IL- 6 and TNF $\alpha$, hence activating an adaptive immune response [49].

Especially IFN $\alpha$ is produced after TLR7 or TLR9 triggering [34-37, 50]. IL-12, a cytokine commonly produced by mDCs and moDCs after TLR stimulation, is not secreted by pDCs as found in the majority of the studies. Only Jarrossay et al. [35] mentioned a weak IL-12 response by pDCs, which was possibly due to a polluting $\mathrm{mDC}$ subset in the samples tested.

Some reports showed a minimal expression of TLR1 on pDCs [36, 37, 51]. However, the possible function of TLR1 on pDCs remains ambiguous, especially since its heterodimeric partner TLR2 is not expressed by pDCs and pDCs do not respond to TLR1/TLR2 ligands [35-38].

Interestingly, pDCs do not express TLR3 and TLR8. Since both TLR3 and TLR8 bind viral ligands and pDCs are specialized in the recognition of viral pathogens, it would not be unlikely for pDCs to express these receptors. Possibly, TLR8 lost its function during evolution as TLR7 binds the same ligands and shares the same signaling pathway, leading to similar effects. However, why pDCs lack TLR3 expression is still unknown.

Surprisingly, pDCs also express TLR10, both at the mRNA and protein level [37, 51, 52], but the function and binding partner of TLR10 are yet to be identified. Overall, human pDCs only express TLR7, 9 and 10 and react on TLR7 and TLR9 activation by secreting type I IFNs, especially IFN $\alpha$.

Practical limitations

When comparing data obtained by different groups, we noticed inconsistencies between studies, which may be caused by technical limitations. For instance, several different techniques to isolate fresh mDCs and pDCs from blood were used by different groups, including cell sorting by FACS and magnetic beads. Even small impurities in the isolated cell population can interfere with the results, as was demonstrated by the IL-12 secretion by a small contaminating $\mathrm{mDC}$ subpopulation, which was first contributed to the pDC population $[34,37,50]$. In addition, most expression profiling of TLRs on DCs is performed by RT-PCR, because of a lack of antibodies directed against TLR molecules. But when antibodies were used, several of them proved to be unreliable as demonstrated by Matsumoto et al. [38] who showed that a TLR3-specific antibody also bound to a centrosomal protein that shared an epitope with TLR3 and incorrectly suggested TLR3 protein expression in pDCs, although TLR3 mRNA expression was absent. 
Even small impurities in the isolated cells $(\sim 1-5 \%)$ can cause problems. Furthermore, interpretation of mRNA expression level is highly subjective and does not always correlate with the expression level of the encoded protein. In addition, mRNA levels do not reveal the localization of the protein. Perhaps TLR proteins residing in intracellular compartments and showing high mRNA expression are only effective when transported to another compartment or to the extracellular membrane after stimulation. For instance, it has been demonstrated that the ectodomain of TLR9 is cleaved in the endolysosome before TLR9 is transported to endosomal compartments and that only the cleaved form of TLR9 is functional after ligand binding [53]. In addition, post-translational modification, such as ubiquitination, may affect TLR expression and functionality [54]. Therefore, next to TLR expression profiling, functional studies using TLR ligands are important in establishing whether the TLR expressed in a given DC subtype is functional. However, cytokine responses and DC maturation may also be caused by non-TLR receptors, such as C-type lectins or undiscovered TLRs that recognize the same pathogenic ligands. In addition, it is very important to use highly purified TLR ligands, since minor contaminations of, for instance, endotoxin may obscure the results.

\section{Implications for immunotherapy of cancer}

The above summarized data suggest that mDCs mainly recognize and respond to bacterial and fungal antigens, whereas pDCs are specialized for viral recognition. However, although $\mathrm{pDC}$ and $\mathrm{mDC}$ subsets have different functional specialization, as they express a different repertoire of TLRs and respond dissimilarly to microbial stimuli, both pDCs and mDCs may be of importance for the induction of anti-tumor responses in DC vaccination therapy. MDCs as well as pDCs can induce Th1 responses after TLR stimulation [34] and anti-tumor responses induced by pDCs have been reported in animal models $[55,56]$.

\section{Reactivation of tumor-infiltrating DCs}

Several studies suggest that human pDCs have the ability to infiltrate solid tumors since they are found in a wide variety of human cancers, including breast cancer [57], head and neck cancer [58] and ovarian cancer [59]. Soluble factors secreted by the tumor create a suppressive environment, thus preventing differentiation and maturation of infiltrating DCs [60-62]. Despite their ability to infiltrate solid tumors, $\mathrm{pDCs}$ on the site are unable to sense DNA via TLRs and become activated.
These findings have been correlated with poor prognosis [57] and are linked to the induction of regulatory T cells [63]. Although pDCs at the tumor site have a pre-pDC phenotype and maintain the immunosuppressive environment, several studies have now demonstrated that topical TLR7-agonist (Imiquimod) treatment led to enhanced pDC recruitment and type I IFN production by resident $\mathrm{pDCs}$ at the tumor site, which in turn generated an inflammatory environment resulting in tumor regression [64, 65]. Furthermore, activation of resident tumor pDCs can also be achieved by intratumoral injection of CpG motifs inducing TLR9 triggering. This strategy has therapeutic potential in patients with basal cell carcinoma and melanoma skin metastases [66]. Since TLR9 is believed to be expressed only on pDCs, $\mathrm{CpG}$ injection will not directly activate mDCs. Therefore, intratumoral injection of other TLR ligands, such as the TLR7/8 ligand $\mathrm{R} 848$ that activates both $\mathrm{mDCs}$ and $\mathrm{pDCs}$, will be even more potent in reactivating DCs at the tumor site and might favor the induction of anti-tumor immune responses.

\section{DC vaccination with $\mathrm{pDCs}$ and $\mathrm{mDCs}$}

Recent studies suggest that $\mathrm{pDC}$ and $\mathrm{mDC}$ cooperate and act synergistically (Fig. 1). In mice, pDCs not only directly induce tumor antigen-specific $\mathrm{CD}^{+} \mathrm{T}$ cell immune responses, but also enhance the ability of $\mathrm{mDCs}$ to present tumor antigens to T cells [67]. Moreover, human mDCs and pDCs activate each other after specific stimulation of only one of the DC subsets with appropriate TLR ligands in vitro [68]. These studies suggest that also in a clinical setting, such as DC vaccination in cancer patients, vaccination with both pDCs and mDCs may generate stronger anti-tumor responses than vaccination with moDCs alone.

We recently completed a clinical trial with tumor antigen-loaded, TLR ligand-matured pDCs in stage IV melanoma patients, which appeared feasible and safe (manuscript in preparation). In the majority of patients vaccinated with pDCs, we found responses against the monitoring protein, demonstrating that even small numbers of naturally occurring DCs can induce immunological responses. When $\mathrm{mDCs}$ and $\mathrm{pDCs}$ would be used in combination, both DC subsets will need stimulation with carefully selected TLR ligands, due the fact that they express a different repertoire of TLRs (Table 1; Fig. 1). Since TLRs act in synergy [69], the combination of different TLR ligands may even be more potent (Fig. 1). It is of importance to find TLR ligands that either induce optimal maturation of both $\mathrm{mDCs}$ and $\mathrm{pDCs}$, or at least do not interfere with maturation of either DC subtype. Future studies will address whether mDC-pDC cross talk can improve antitumor responses in cancer patients. 


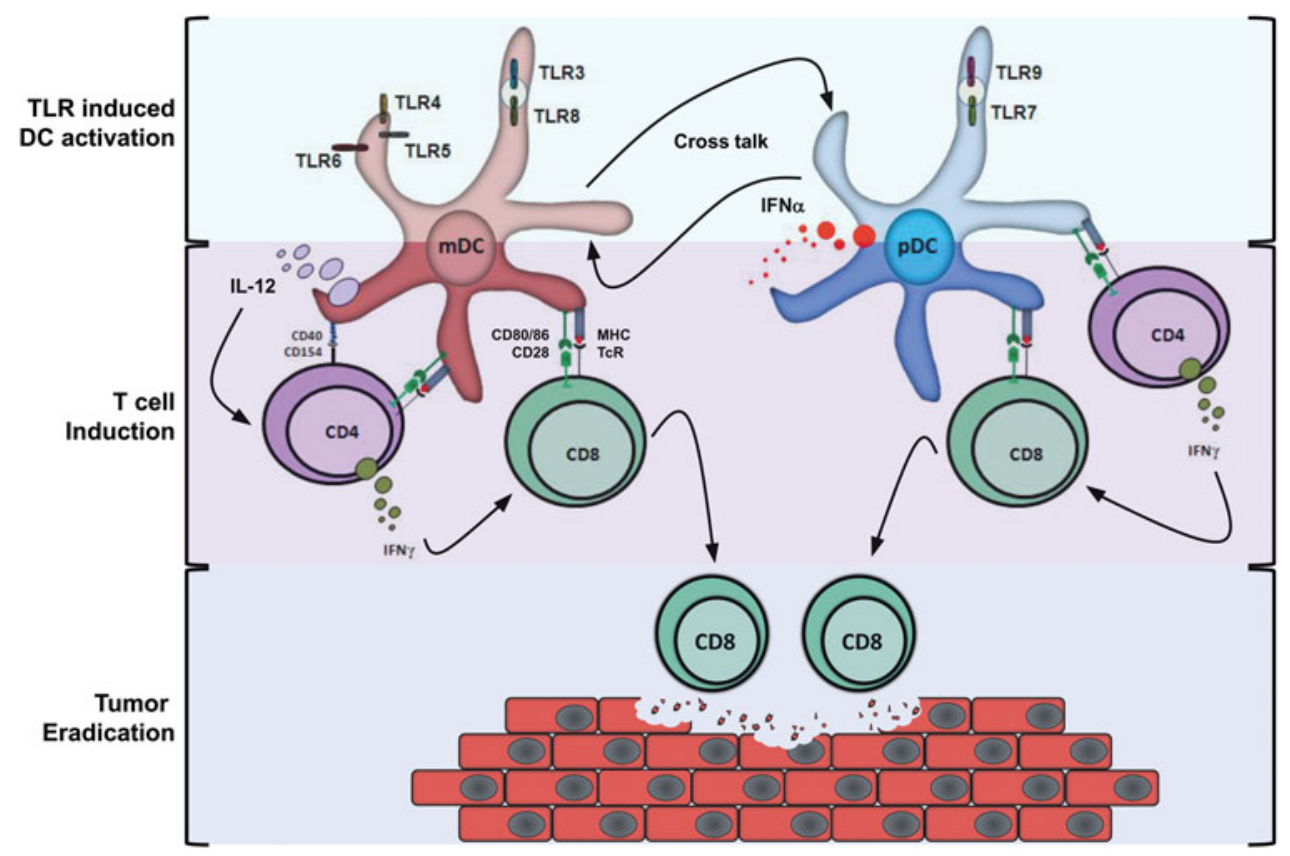

Fig. 1 TLR activation of human DC subsets can enhance anti-tumor responses in vivo. DC subsets express a wide repertoire of TLRs, which upon triggering induce the activation of the DC. Where pDCs predominantly express TLRs in endosomal compartments, mDCs have a broader TLR expression pattern, both at the endosomal and extracellular membranes. By cross talk between mDCs and pDCs, either by cell-cell contact or soluble factors such as type I IFNs, TLR-induced activation of one subset can lead to the activation of the other subset. Type I IFNs appear to yield more potent $\mathrm{mDCs}$ in terms of IL-12 secre-

\section{Concluding remarks}

To date, most clinical studies apply moDCs for DC vaccination of cancer patients. As described above, culturing procedures required to obtain moDCs may affect their ability to induce anti-tumor immunity. We hypothesize that TLR-matured blood DCs may be a potent alternative, since these cells do not require extensive culturing and can be isolated in a closed system in accordance to GMP standards. Despite their low frequencies, human naturally occurring DCs may have superior migratory and antigenpresenting capacities compared to in vitro-generated moDCs, especially when combining different DC subsets. Alternatively, the potency of in vitro-generated moDCs could be improved by electroporation with mRNA-encoding proteins involved in DC maturation, migration and $\mathrm{T}$ cell activation, as was suggested by Bonehill et al. [70]. Future studies will need to prove the feasibility and potency of TLR-matured DC subsets for DC-based immunotherapy.

Acknowledgments This work was supported by grants from the Dutch Cancer Society (KWF 2003-2917, KWF 2004-3126, KWF 2004-3127, KWF 2006-3699), the Netherlands Organization for Scientific Research (NWO ZonMW, Vidi grant 917.76.363, Vici grant 918.66.615), the TIL-foundation, the NOTK-foundation and the EU tion, induction of tumor-specific cytotoxic T cells and Th1 responses in vitro. On direct TLR activation, mDCs gain the ability to secrete large quantities of IL-12, which is beneficial for the polarization of a Th1 response. Both $\mathrm{mDCs}$ and $\mathrm{pDCs}$ have the capacity to evoke $\mathrm{T}$ helper cell responses. Moreover, pDCs can promote the ability of $\mathrm{mDCs}$ to cross-prime $\mathrm{CD} 8^{+} \mathrm{T}$ cells. Consequently, TLR activation of mDCs and pDCs and the cross talk between those two subsets can strongly enhance anti-tumor responses in vivo

(Cancerimmunotherapy, LSHC-CT-2006-518234 and DC-Thera, LSHBCT-2004-512074).

\section{References}

1. Lesterhuis WJ, de Vries IJM, Adema GJ, Punt CJA (2004) Dendritic cell-based vaccines in cancer immunotherapy: an update on clinical and immunological results. Ann Oncol 15:145-151

2. Lesterhuis WJ, Aarntzen EHJG, Vries IJM, Schuurhuis DH, Figdor CG, Adema GJ, Punt CJA (2008) Dendritic cell vaccines in melanoma: from promise to proof? Crit Rev Oncol Hematol 66:118-134

3. Breckpot K, Corthals J, Bonehill A, Michiels A, Tuyaerts S, Aerts C, Heirman C, Thielemans K (2005) Dendritic cells differentiated in the presence of IFN-beta and IL-3 are potent inducers of an antigen-specific CD8(+) T cell response. J Leukocyte Biol 78:898908

4. Soruri A, Kiafard Z, Dettmer C, Riggert J, Kohl J, Zwirner J (2003) IL-4 down-regulates anaphylatoxin receptors in monocytes and dendritic cells and impairs anaphylatoxin-induced migration in vivo. J Immunol 170:3306-3314

5. de Vries IJM, Lesterhuis WJ, Scharenborg NM, Engelen LPH, Ruiter DJ, Gerritsen MJP, Croockewit S, Britten CM, Torensma R, Adema GJ, Figdor CG, Punt CJA (2003) Maturation of dendritic cells is a prerequisite for inducing immune responses in advanced melanoma patients. Clin Cancer Res 9:5091-5100

6. Netea MG, Van der Meer JWM, Sutmuller RP, Adema GJ, Kullberg BJ (2005) From the Th1/Th2 paradigm towards a 
toll-like receptor/T-helper bias. Antimicrob Agents Chemother 49:3991-3996

7. Banchereau J, Steinman RM (1998) Dendritic cells and the control of immunity. Nature 392:245-252

8. Shortman K, Liu YJ (2002) Mouse and human dendritic cell subtypes. Nat Rev Immunol 2:151-161

9. Dzionek A, Fuchs A, Schmidt P, Cremer S, Zysk M, Miltenyi S, Buck DW, Schmitz J (2000) BDCA-2, BDCA-3 and BDCA-4: three markers for distinct subsets of dendritic cells in human peripheral blood. J Immunol 165:6037-6046

10. Colonna M, Trinchieri G, Liu YJ (2004) Plasmacytoid dendritic cells in immunity. Nat Immunol 5:1219-1226

11. Corcoran L, Ferrero I, Vremec D, Lucas K, Waithman J, O'Keeffe M, Wu L, Wilson A, Shortman K (2003) The lymphoid past of mouse plasmacytoid cells and thymic dendritic cells. J Immunol 170:4926-4932

12. D'Amico A, Wu L (2003) The early progenitors of mouse dendritic cells and plasmacytoid predendritic cells are within the bone marrow hemopoietic precursors expressing Flt3. J Exp Med 198:293-303

13. Karsunky H, Merad M, Cozzio A, Weissman IL, Manz MG (2003) Flt3 ligand regulates dendritic cell development from Flt3(+) lymphoid and myeloid-committed progenitors to Flt3(+) dendritic cells in vivo. J Exp Med 198:305-313

14. Hochrein H, Schlatter B, O'Keeffe M, Wagner C, Schmitz F, Schiemann M, Bauer S, Suter M, Wagner H (2004) Herpes simplex virus type-1 induces IFN-alpha production via Toll-like receptor 9-dependent and -independent pathways. Proc Natl Acad Sci U S A 101:11416-11421

15. Schakel K, Mayer E, Federle C, Schmitz M, Riethmuller G, Rieber EP (1998) A novel dendritic cell population in human blood: onestep immunomagnetic isolation by a specific $\mathrm{mAb}$ (M-DC8) and in vitro priming of cytotoxic $\mathrm{T}$ lymphocytes. Eur $\mathrm{J}$ Immunol 28:4084-4093

16. MacDonald KPA, Munster DJ, Clark GJ, Dzionek A, Schmitz J, Hart DNJ (2002) Characterization of human blood dendritic cell subsets. Blood 100:4512-4520

17. Piccioli D, Tavarini S, Borgogni E, Steri V, Nuti S, Sammicheli C, Bardelli M, Montagna D, Locatelli F, Wack A (2007) Functional specialization of human circulating CD16 and CD1c myeloid dendritic-cell subsets. Blood 109:5371-5379

18. Lindstedt M, Lundberg K, Borrebaeck CAK (2005) Gene family clustering identifies functionally associated subsets of human in vivo blood and tonsillar dendritic cells. J Immunol 175:4839-4846

19. Huysamen C, Willment JA, Dennehy KM, Brown GD (2008) CLEC9A is a novel activation C-type lectin-like receptor expressed on BDCA3(+) dendritic cells and a subset of monocytes. J Biol Chem 283:16693-16701

20. Sallusto F, Lanzavecchia A (1994) Efficient presentation of soluble-antigen by cultured human dendritic cells is maintained by granulocyte-macrophage colony-stimulating factor plus interleukin-4 and down-regulated by tumor-necrosis-factor-alpha. J Exp Med 179:1109-1118

21. Figdor CG, de Vries IJM, Lesterhuis WJ, Melief CJM (2004) Dendritic cell immunotherapy: mapping the way. Nat Med 10:475480

22. Wilson NS, El Sukkari D, Belz GT, Smith CM, Steptoe RJ, Heath WR, Shortman K, Villadangos JA (2003) Most lymphoid organ dendritic cell types are phenotypically and functionally immature. Blood 102:2187-2194

23. Jefford M, Schnurr M, Toy T, Masterman KA, Shin A, Beecroft T, Tai TY, Shortman K, Shackleton M, Davis ID, Parente P, Luft T, Chen WS, Cebon J, Maraskovsky E (2003) Functional comparison of DCs generated in vivo with Flt3 ligand or in vitro from blood monocytes: differential regulation of function by specific classes of physiologic stimuli. Blood 102:1753-1763
24. Osugi Y, Vuckovic S, Hart DNJ (2002) Myeloid blood CD11c(+) dendritic cells and monocyte-derived dendritic cells differ in their ability to stimulate T lymphocytes. Blood 100:2858-2866

25. Banchereau J, Palucka AK, Dhodapkar M, Burkeholder S, Taquet N, Rolland A, Taquet S, Coquery S, Wittkowski KM, Bhardwaj N, Pineiro L, Steinman R, Fay J (2001) Immune and clinical responses in patients with metastatic melanoma to CD34(+) progenitorderived dendritic cell vaccine. Cancer Res 61:6451-6458

26. Akira S, Uematsu S, Takeuchi O (2006) Pathogen recognition and innate immunity. Cell 124:783-801

27. Iwasaki A, Medzhitov R (2004) Toll-like receptor control of the adaptive immune responses. Nat Immunol 5:987-995

28. Yarovinsky F, Zhang DK, Andersen JF, Bannenberg GL, Serhan CN, Hayden MS, Hieny S, Sutterwala FS, Flavell RA, Ghosh S, Sher A (2005) TLR11 activation of dendritic cells by a protozoan profilin-like protein. Science 308:1626-1629

29. Zhang DK, Zhang GL, Hayden MS, Greenblatt MB, Bussey C, Flavell RA, Ghosh S (2004) A toll-like receptor that prevents infection by uropathogenic bacteria. Science 303:1522-1526

30. Asea A, Rehli M, Kabingu E, Boch JA, Bare O, Auron PE, Stevenson MA, Calderwood SK (2002) Novel signal transduction pathway utilized by extracellular HSP70_-role of Toll-like receptor (TLR) 2 AND TLR4. J Biol Chem 277:15028-15034

31. Vabulas RM, Braedel S, Hilf N, Singh-Jasuja H, Herter S, AhmadNejad P, Kirschning CJ, da Costa C, Rammensee HG, Wagner H, Schild H (2002) The endoplasmic reticulum-resident heat shock protein Gp96 activates dendritic cells via the toll-like receptor 2/4 pathway. J Biol Chem 277:20847-20853

32. Akira S, Takeda K (2004) Toll-like receptor signalling. Nat Rev Immunol 4:499-511

33. Hovanessian AG (2007) On the discovery of interferon-inducible, double-stranded RNA activated enzymes: the $2^{\prime}-5$ 'oligoadenylate synthetases and the protein kinase PKR. Cytokine Growth Factor Rev 18:351-361

34. Ito T, Amakawa R, Kaisho T, Hemmi H, Tajima K, Uehira K, Ozaki Y, Tomizawa H, Akira S, Fukuhara S (2002) Interferonalpha and interleukin-12 are induced differentially by toll-like receptor 7 ligands in human blood dendritic cell subsets. J Exp Med 195:1507-1512

35. Jarrossay D, Napolitani G, Colonna M, Sallusto F, Lanzavecchia A (2001) Specialization and complementarity in microbial molecule recognition by human myeloid and plasmacytoid dendritic cells. Eur J Immunol 31:3388-3393

36. Kadowaki N, Ho S, Antonenko S, Malefyt RD, Kastelein RA, Bazan F, Liu YJ (2001) Subsets of human dendritic cell precursors express different toll-like receptors and respond to different microbial antigens. J Exp Med 194:863-869

37. Krug A, Towarowski A, Britsch S, Rothenfusser S, Hornung V, Bals R, Giese T, Engelmann H, Endres S, Krieg AM, Hartmann G (2001) Toll-like receptor expression reveals CpG DNA as a unique microbial stimulus for plasmacytoid dendritic cells which synergizes with CD40 ligand to induce high amounts of IL-12. Eur J Immunol 31:3026-3037

38. Matsumoto M, Funami K, Tanabe M, Oshiumi H, Shingai M, Seto Y, Yamamoto A, Seya T (2003) Subcellular localization of tolllike receptor 3 in human dendritic cells. J Immunol 171:3154 3162

39. Means TK, Hayashi F, Smith KD, Aderem A, Luster AD (2003) The toll-like receptor 5 stimulus bacterial flagellin induces maturation and chemokine production in human dendritic cells. J Immunol 170:5165-5175

40. Muzio M, Bosisio D, Polentarutti N, D'amico G, Stoppacciaro A, Mancinelli R, van't Veer C, Penton-Rol G, Ruco LP, Allavena P, Mantovani A (2000) Differential expression and regulation of tolllike receptors (TLR) in human leukocytes: selective expression of TLR3 in dendritic cells. J Immunol 164:5998-6004 
41. Renn CN, Sanchez DJ, Ochoa MT, Legaspi AJ, Oh CK, Liu PT, Krutzik SR, Sieling PA, Cheng GH, Modlin RL (2006) TLR activation of Langerhans cell-like dendritic cells triggers an antiviral immune response. J Immunol 177:298-305

42. Hochrein H, O'Keeffe M (2008) Dendritic cell subsets and Tolllike receptors. In: Bauer S, Hartmann G (eds) Toll-like receptors (TLRs) and innate immunity. Handb Exp Pharmacol, vol 183. Springer, Berlin, pp 153-179

43. Bell MP, Svingen PA, Rahman MK, Xiong Y, Faubion WA (2007) FOXP3 regulates TLR10 expression in human T regulatory cells. J Immunol 179:1893-1900

44. Visintin A, Mazzoni A, Spitzer JH, Wyllie DH, Dower SK, Segal DM (2001) Regulation of Toll-like receptors in human monocytes and dendritic cells. J Immunol 166:249-255

45. Fitzgerald KA, McWhirter SM, Faia KL, Rowe DC, Latz E, Golenbock DT, Coyle AJ, Liao SM, Maniatis T (2003) IKK epsilon and TBK1 are essential components of the IRF3 signaling pathway. Nat Immunol 4:491-496

46. Gilliet M, Cao W, Liu YJ (2008) Plasmacytoid dendritic cells: sensing nucleic acids in viral infection and autoimmune diseases. Nat Rev Immunol 8:594-606

47. Chockalingam A, Brooks JC, Cameron JL, Blum LK, Leifer CA (2009) TLR9 traffics through the Golgi complex to localize to endolysosomes and respond to CpG DNA. Immunol Cell Biol 87:209-217

48. Latz E, Schoenemeyer A, Visintin A, Fitzgerald KA, Monks BG, Knetter CF, Lien E, Nilsen NJ, Espevik T, Golenbock DT (2004) TLR9 signals after translocating from the ER to CpG DNA in the lysosome. Nat Immunol 5:190-198

49. Guiducci C, Ott G, Chan JH, Damon E, Calacsan C, Matray T, Lee KD, Man RLC, Barrat FJ (2006) Properties regulating the nature of the plasmacytoid dendritic cell response to Toll-like receptor 9 activation. J Exp Med 203:1999-2008

50. Hornung V, Rothenfusser S, Britsch S, Krug A, Jahrsdorfer B, Giese T, Endres S, Hartmann G (2002) Quantitative expression of Toll-like receptor 1-10 mRNA in cellular subsets of human peripheral blood mononuclear cells and sensitivity to $\mathrm{CpG}$ oligodeoxynucleotides. J Immunol 168:4531-4537

51. Flacher V, Bouschbacher M, Verronese E, Massacrier C, Sisirak V, Berthier-Vergnes O, Saint-Vis B, Caux C, Dezutter-Dambuyant C, Lebecque S, Valladeau J (2006) Human Langerhans cells express a specific TLR profile and differentially respond to viruses and Gram-positive bacteria. J Immunol 177:7959-7967

52. Hasan U, Chaffois C, Gaillard C, Saulnier V, Merck E, Tancredi S, Guiet C, Briere F, Vlach J, Lebecque S, Trinchieri G, Bates EEM (2005) Human TLR10 is a functional receptor, expressed by B cells and plasmacytoid dendritic cells, which activates gene transcription through MyD88. J Immunol 174:2942-2950

53. Ewald SE, Lee BL, Lau L, Wickliffe KE, Shi GP, Chapman HA, Barton GM (2008) The ectodomain of Toll-like receptor 9 is cleaved to generate a functional receptor. Nature 456:658-662

54. Chuang TH, Ulevitch RJ (2004) Triad3A, an E3 ubiquitin-protein ligase regulating Toll-like receptors. Nat Immunol 5:495-502

55. Boonstra A, Asselin-Paturel C, Gilliet M, Crain C, Trinchieri G, Liu YJ, O'Garra A (2003) Flexibility of mouse classical and plasmacytoid-derived dendritic cells in directing T helper type 1 and 2 cell development: dependency on antigen dose and differential toll-like receptor ligation. J Exp Med 197:101-109

56. Salio M, Cella M, Vermi W, Facchetti F, Palmowski MJ, Smith CL, Shepherd D, Colonna M, Cerundolo V (2003) Plasmacytoid dendritic cells prime IFN-gamma-secreting melanoma-specific CD8 lymphocytes and are found in primary melanoma lesions. Eur J Immunol 33:1052-1062
57. Treilleux I, Blay JY, Bendriss-Vermare N, Ray-Coquard I, Bachelot T, Guastalla JP, Bremond A, Goddard S, Pin JJ, Barthelemy-Dubois C, Lebecque S (2004) Dendritic cell infiltration and prognosis of early stage breast cancer. Clin Cancer Res 10:7466-7474

58. Hartmann E, Wollenberg B, Rothenfusser S, Wagner M, Wellisch D, Mack B, Giese T, Gires O, Endres S, Hartmann G (2003) Identification and functional analysis of tumor-infiltrating plasmacytoid dendritic cells in head and neck cancer. Cancer Res 63:64786487

59. Zou WP, Machelon V, Coulomb-L'Hermin A, Borvak J, Nome F, Isaeva T, Wei S, Krzysiek R, Durand-Gasselin I, Gordon A, Pustilnik T, Curiel DT, Galanaud P, Capron F, Emilie D, Curiel TJ (2001) Stromal-derived factor-1 in human tumors recruits and alters the function of plasmacytoid precursor dendritic cells. Nat Med 7:1339-1346

60. Gabrilovich DI, Corak J, Ciernik IF, Kavanaugh D, Carbone DP (1997) Decreased antigen presentation by dendritic cells in patients with breast cancer. Clin Cancer Res 3:483-490

61. Bell D, Chomarat P, Broyles D, Netto G, Harb GM, Lebecque S, Valladeau J, Davoust J, Palucka KA, Banchereau J (1999) In breast carcinoma tissue, immature dendritic cells reside within the tumor, whereas mature dendritic cells are located in peritumoral areas. J Exp Med 190:1417-1425

62. Menetrier-Caux C, Montmain G, Dieu MC, Bain C, Favrot MC, Caux C, Blay JY (1998) Inhibition of the differentiation of dendritic cells from CD34(+) progenitors by tumor cells: role of interleukin-6 and macrophage colony-stimulating factor. Blood 92:4778-4791

63. Wei S, Kryczek I, Zou LH, Daniel B, Cheng P, Mottram P, Curiel T, Lange A, Zou WP (2005) Plasmacytoid dendritic cells induce $\mathrm{CD} 8(+)$ regulatory $\mathrm{T}$ cells in human ovarian carcinoma. Cancer Res 65:5020-5026

64. Dummer R, Urosevic M, Kempf W, Hoek K, Hafner J, Burg G (2003) Imiquimod in basal cell carcinoma: how does it work? Br J Dermatol 149:57-58

65. Miller RL, Gerster JF, Owens ML, Slade HB, Tomai MA (1999) Imiquimod applied topically: a novel immune response modifier and new class of drug. Int J Immunopharmacol 21:1-14

66. Hofmann MA, Kors C, Audring H, Walden P, Sterry W, Trefzer U (2008) Phase 1 evaluation of intralesionally injected TLR9-agonist PF-3512676 in patients with basal cell carcinoma or metastatic melanoma. J Immunother 31:520-527

67. Lou YY, Liu CW, Kim GJ, Liu YJ, Hwu P, Wang G (2007) Plasmacytoid dendritic cells synergize with myeloid dendritic cells in the induction of antigen-specific antitumor immune responses. J Immunol 178:1534-1541

68. Piccioli D, Sammicheli C, Tavarini S, Nuti S, Frigimelica E, Manetti AGO, Nuccitelli A, Aprea S, Valentini S, Borgogni E, Wack A, Valiante NM (2009) Human plasmacytoid dendritic cells are unresponsive to bacterial stimulation and require a novel type of cooperation with myeloid dendritic cells for maturation. Blood 113:4232-4239

69. Trinchieri G, Sher A (2007) Cooperation of Toll-like receptor signals in innate immune defence. Nat Rev Immunol 7:179-190

70. Bonehill A, Tuyaerts S, Van Nuffel AM, Heirman C, Bos TJ, Fostier K, Neyns B, Thielemans K (2008) Enhancing the T-cell stimulatory capacity of human dendritic cells by co-electroporation with CD40L, CD70 and constitutively active TLR4 encoding mRNA. Mol Ther 16:1170-1180

71. Kokkinopoulos I, Jordan WJ, Ritter MA (2005) Toll-like receptor mRNA expression patterns in human dendritic cells and monocytes. Mol Immunol 42:957-968 